\title{
Evaluation of Length of Hospital Stay Joining Educational Programs for Type 2 Diabetes Mellitus Patients: Can We Control Medical Costs in Japan?
}

\author{
Kazumitsu Nawata1, Koichi Kawabuchi ${ }^{2}$ \\ ${ }^{1}$ Graduate School of Engineering, University of Tokyo, Tokyo, Japan \\ ${ }^{2}$ Graduate School of Medical and Dental Sciences, Tokyo Medical and Dental University, Tokyo, Japan \\ Email: nawata@tmi.t.u-tokyo.ac.jp, kawabuchi.hce@tmd.ac.jp
}

Received 20 January 2015; accepted 13 February 2015; published 16 February 2015

Copyright (C) 2015 by authors and Scientific Research Publishing Inc.

This work is licensed under the Creative Commons Attribution International License (CC BY).

http://creativecommons.org/licenses/by/4.0/

\section{(c) (1) Open Access}

\section{Abstract}

Diabetes has become a growing concern in Japan, both medically and financially. The medical cost of diabetes was estimated at 1215 billion yen for fiscal year 2011. We analyzed the length of stay (LOS) in a hospital for type 2 diabetes mellitus patients who participated in educational programs to determine factors affecting LOS. Data on 991 patients obtained from 28 Red Cross hospitals in 2008 were used. For the analysis, we used the Box-Cox transformation model and Hausman test. The results revealed that patients aged 75 years and above and those with comorbidities and complications were prone to longer LOS. The analysis also revealed significant differences in LOS across the hospitals, even after controlling for patient characteristics. Finally, we applied the least squares method to determine the effects of hospital and regional factors and revealed that patients' LOS was affected by the region's average LOS. Regional corporations and networks appeared to be important in improving educational programs.

\section{Keywords}

Medical Cost, Diabetes, Type 2 Diabetes Mellitus Patients, Length of Stay (LOS), Educational Program, Box-Cox Transformation Model

\section{Introduction}

The growing incidence of diabetes has become both a medical and financial concern in Japan. In fiscal year 
2011, the medical costs for diabetes were estimated at 1215 billion yen or 3.1\% of Japan's total medical expenditure (38,585 billion yen) [1]. However, this concern is not limited to Japan. In fact, studies have reported that the number of diabetes patients worldwide has increased from 153 million in 1980 to 347 million in 2008 [2]. More recently, the American Diabetes Association [3] estimated the total cost of diagnosed diabetes in the United States at $\$ 245$ billion in 2012, comprising \$176 billion as direct medical costs and \$69 billion from reduced productivity. In Australia, the proportion of individuals with diabetes increased from $1.5 \%$ of the total population in 1989-1990 to $4.1 \%$ in 2007-2008; diabetes accounted for $2 \%$ of total medical expenses and one out of every 25 cases requiring hospitalization in 2009-2010 [4].

This study analyzes the length of stay (LOS) in Japanese hospitals for type 2 diabetes mellitus (hereafter, diabetic) patients who participated in educational programs (hereafter, educational hospitalization) to identify factors affecting their LOS. Type 2 diabetic patients represent more than $90 \%$ of diabetic patients in Japan. The diagnostic indicator is insufficient insulin resulting from reduced insulin secretion; however, the causes of the disease are still unknown [5]. Diabetes is the only disease that qualifies for educational hospitalization in Japan. Educational programs largely focus on lifestyle improvement guidance, such as improved diet and exercises, rather than medical treatment. Healy et al. [6] analyzed inpatient diabetes education (IDE) in an American hospital and concluded that "Formal IDE was independently associated with a lower frequency of all-cause hospital readmission within 30 days; this relationship was attenuated by 180 days.” LOS significantly influences medical costs associated with educational hospitalization. A problem currently faced in the Japanese medical system is the prolonged average length of stay (ALOS). In 2009 [7], ALOS with diabetes as first-listed diagnosis was 5.0 days in the United States, whereas the present study reports that the ALOS of diabetes patients in Japan was 18.3 days.

Reducing ALOS can benefit the Japanese society in two ways. First is a reduction in the direct cost of hospitalization, given that nearly one-third type 2 diabetic patients participate in educational hospitalization programs in our dataset. Second is the indirect benefit of the prevention and good management of diabetes. Kudo et al. [8] reviewed 2,120,170 records of acute patients and found that 1) type 2 diabetes was observed in $11.4 \%$ patients, and $9.9 \%$ had diabetes as a comorbidity; 2) total LOS in a hospital for all diabetic patients was 33,468,152 bed days (i.e., 13.9\% of total bed days); and 3) patients with type 2 diabetes as a comorbidity had prolonged LOSthe median LOS with and without diabetes was 9 and 13 days, respectively. Ncube-Zulu and Danckwerts [9] analyzed data for 407 patients with and without diabetes in South Africa and derived similar results- the average total hospitalization cost per patient was significantly higher and ALOS was longer for patients with diabetes than those without. Inoue et al. [10] also pointed out the risk of cancer in diabetic patients. In addition, various authors suggested that comorbid diabetes prolongs LOS and increases the risk of fatality due to hyperglycaemia [11], chronic obstructive pulmonary disease [12], foot disease [13], fracture of the femur [14], spinal surgery [15], and cardiovascular diseases [16]. Hence, the true cost of diabetes is probably much higher than the direct one. Simply put, reducing LOS lowers costs incurred by diabetic patients and allows more patients to join educational programs aimed at helping patients prevent and control diabetes. This, in turn, could reduce the overall medical expenses in Japan.

However, not many studies have been conducted on the LOS of patients with diabetes in Japan. Although Mutou et al. [17] analyzed data for such patients under the age of 18, they did not use an econometric model. As mentioned, LOS accounts for a large portion of medical costs incurred during educational hospitalization. Thus, another major objective of this study is to evaluate whether hospitals influence patients' LOS. If there are significant differences in ALOS among hospitals, ALOS can be reduced by improving educational programs in hospitals with prolonged ALOS. However, LOS may also depend on patients' conditions. Hospitals with many patients requiring special care are likely to report prolonged ALOS. Therefore, it is necessary to control for patient characteristics using an econometric model. Sohmiya et al. [18] analyzed LOS by conducting a regression analysis on data for 313 patients, although their study was restricted to one hospital.

In April 2003, Japan introduced a new medical inclusive payment system based on the diagnosis procedure combination (DPC). The system is now called the DPC/per diem payment system (PDPS) [19]. As of April 2014, 1585 hospitals with a total of 492,206 beds were included in DPC/PDPS (hereafter, DPC hospitals) [20]. In June 2013, Japan reported a total of 7483 general hospitals with 897,749 beds [21], of which DPC hospitals accounted for $21 \%$ and 55\%, respectively. For details on DPC and DPC/PDPS, see Nawata et al. [22]. Presently, medical information on DPC hospitals is computerized, making it possible to use large-scale datasets. However, the effective use of these datasets has become an increasing concern [23]. 
This study analyzed educational hospitalization LOS for diabetic patients using data for 991 patients from 28 Red Cross hospitals in 2008. To do so, we first adopted the Box-Cox [24] transformation model (hereafter, BC model). Next, drawing on previous studies, we tested the assumption that the maximum likelihood estimator (hereafter, BC MLE) under the normality assumption is a consistent estimator [25]-[28], followed by an analysis of the LOS using the method confirmed by the tests. Finally, we analyzed hospital and regional factors that might affect LOS.

\section{Box-Cox (BC) Model}

\subsection{BC Model and BC Maximum Likelihood Estimator}

We used the BC model to analyze the LOS of diabetic patients:

$$
\begin{aligned}
& \frac{y_{t}^{\lambda}}{\lambda}, \quad \text { if } \lambda \neq 0 ; \\
& z_{t}=\log \left(y_{t}\right), \quad \text { if } \lambda=0 ; \\
& z_{t}=x_{t}^{\prime} \beta+u_{t}, \quad y_{t} \geq 0, \quad t=1,2, \cdots, T .
\end{aligned}
$$

where $y_{t}$ is LOS, $\lambda$ is the transformation parameter, and $x_{t}$ and $\beta$ are the $k$-th dimensional vectors of the explanatory variables and coefficients, respectively. Let $\varphi$ be the probability density function of the standard normal assumption. BC MLE is obtained by maximizing the likelihood function given by

$$
\begin{aligned}
& \log L(\theta)=\sum_{t} \log f_{t}(\theta) \\
& \log f_{t}(\theta)=\log \varphi\left\{\left(z_{t}-x_{t}^{\prime} \beta\right) / \sigma\right\}-\log \sigma+(\lambda-1) \log y_{t} .
\end{aligned}
$$

where $\sigma^{2}$ is the variance of $u_{t}$ and $\theta^{\prime}=\left(\lambda, \hat{\beta}^{\prime}, \sigma^{2}\right)$. BC MLE is consistent and efficient if the error terms are homoscedastic and the "small $\sigma$ ” assumption [27] [29] is satisfied. Under these assumptions, the asymptotic distribution of BC MLE, $\hat{\theta}_{B C}^{\prime}=\left(\hat{\lambda}_{B C}, \hat{\beta}_{B C}^{\prime}, \hat{\sigma}_{B C}^{2}\right)$, is obtained by

$$
\sqrt{T}\left(\hat{\theta}_{B C}-\theta_{0}\right) \rightarrow N\left[0, A^{-1} B A^{-1}\right]
$$

where $\theta_{0}^{\prime}=\left(\lambda_{0}, \beta_{0}^{\prime}, \sigma_{0}^{2}\right)$ is the true parameter value of $\theta, A=-E\left[\left.\frac{\partial^{2} \log L}{\partial \theta \partial^{\prime}}\right|_{\theta_{0}}\right], \quad B=E\left[\ell_{t}\left(\theta_{0}\right) \ell_{t}\left(\theta_{o}\right)^{\prime}\right]$, and $\ell_{t}(\theta)=\frac{\partial \log f_{i}(\theta)}{\partial \theta}$

\subsection{Testing the "Small $\sigma$ " Assumption}

We suppose that the error terms are homoscedastic. Nawata [25] considered the roots of the equations:

$$
\begin{aligned}
& \begin{array}{l}
G_{T}(\theta)=\sum_{t}\left[-\frac{1}{\sigma^{2} \lambda}\left[\left\{\frac{\log \left(\lambda x_{t}^{\prime} \beta+1\right)}{\lambda}+\frac{z_{t}-x_{t}^{\prime} \beta}{\lambda x_{t}^{\prime} \beta+1}\right\} y_{t}^{\lambda}-z_{t}\right]\left(z_{t}-x_{t}^{\prime} \beta\right)+\frac{1}{\lambda} \log \left(\lambda x_{t}^{\prime} \beta+1\right)+\frac{z-x_{t}^{\prime} \beta}{\lambda x_{t}^{\prime} \beta+1}\right] \\
\quad \equiv \sum_{t} g_{t}(\theta)=0 ;
\end{array} \\
& \frac{\partial \log L(\theta)}{\partial \beta}=\sum_{t} \frac{\partial \log f_{i}(\theta)}{\partial \theta}=\sum_{t} \frac{1}{\sigma^{2}} x_{t}\left(z_{t}-x_{t}^{\prime} \beta\right)=0 ; \\
& \text { and } \frac{\partial \log L(\theta)}{\partial \sigma^{2}}=\sum_{t} \frac{\partial \log f_{i}(\theta)}{\partial \sigma^{2}} \sum_{t} \frac{\left(z_{t}-x_{t}^{\prime} \beta\right)-\sigma^{2}}{2 \sigma^{2}}=0 .
\end{aligned}
$$

$G_{T}(\theta)$ is obtained by approximating $\partial \log L / \partial \lambda$. If the first and third moments of $u_{t}$ are zero, the estimator obtained from Equation (4) (hereafter, the $N$-estimator) is consistent. Let $\hat{\theta}_{N}^{\prime}=\left(\lambda_{N}, \beta_{N}^{\prime}, \sigma_{N}^{2}\right)$ be the 
$N$-estimator. Its asymptotic distribution is given by

$$
\sqrt{T}\left(\hat{\theta}_{N}-\theta_{0}\right) \rightarrow N\left[0, C^{-1} B^{*}\left(C^{\prime}\right)^{-1}\right]
$$

where $C=-E\left[\left.\frac{\partial \ell_{t}(\theta)}{\partial \theta^{\prime}}\right|_{\theta_{0}}\right], \quad B^{*}=E\left[\ell_{t}^{*}\left(\theta_{o}\right) \ell_{t}^{*}\left(\theta_{o}\right)^{\prime}\right]$, and $\ell_{t}^{*}(\theta)^{\prime}=\left[g_{t}(\theta), \frac{\partial \log f_{i}(\theta)}{\partial \beta^{\prime}}, \frac{\partial \log f_{i}(\theta)}{\partial \sigma^{2}}\right]$,

Since $G_{T}\left(\theta_{0}\right)=\left.\frac{\partial \log L}{\partial \lambda}\right|_{\theta_{0}}$ under the small $\sigma$ assumption, $B=B^{*}$ and thus,

$$
\sqrt{T}\left(\hat{\lambda}_{N}-\hat{\lambda}_{B C}\right) \rightarrow N(0, \delta)
$$

where $\delta$ is the $(1,1)$ element of $\left(A^{-1}-C^{-1}\right) B\left(A^{-1}-C^{-1}\right)^{\prime}$. We apply the Hausman test [30] to verify the small $\sigma$ assumption by using $t=\sqrt{T}\left(\hat{\lambda}_{N}-\hat{\lambda}_{\mathrm{BC}}\right) / \sqrt{\hat{\delta}}$ as the test statistic, where $\hat{\delta}$ is the estimator of $\delta$ [27]. Note that no element of $\beta$ can be used in the Hausman test [31].

\subsection{Testing the Assumption of Homoscedasticity}

BC MLE and the $N$-estimator would not be consistent under heteroscedasticity even if the small $\sigma$ assumption were satisfied; therefore, it is also necessary to test the assumption of homoscedasticity as well. Nawata [26] [28] proposed an estimator that is consistent even under heteroscedasticity if $E\left(u_{t} \mid x_{t}\right)=0$ and $E\left(u_{t}^{3} \mid x_{t}\right)=0$. The estimator is obtained by the roots of the equations:

$$
K_{T}(\vartheta)=\sum_{t} k\left(\vartheta, x_{t}, y_{t}\right)=0, \quad k_{t}(\vartheta)=\left(z_{t}-x_{t}^{\prime} \beta\right)^{3} \quad \text { and } \quad \sum_{t} x_{t}\left(z_{t}-x_{t}^{\prime} \beta\right)=0
$$

where $\vartheta^{\prime}=(\lambda, \beta)$. The estimator obtained from Equation (7) (hereafter, robust estimator) is consistent even under heteroscedasticity. The asymptotic distribution of the robust estimator, $\hat{\vartheta}^{\prime}=\left(\hat{\lambda}_{R}, \hat{\beta}_{R}^{\prime}\right)$, is given by

$$
\sqrt{T}\left(\hat{\vartheta}-\vartheta_{0}\right) \rightarrow N\left[0, D^{-1} F\left(D^{\prime}\right)^{-1}\right],
$$

where $\vartheta_{0}^{\prime}=\left(\lambda_{0}, \beta_{0}\right), \quad \psi_{t}(\vartheta)=x_{t}\left(z_{t}-x_{t}^{\prime} \beta\right), \quad \omega_{t}(\vartheta)^{\prime}=\left[k_{t}(\vartheta), \psi_{t}(\vartheta)^{\prime}\right], D=\lim _{T \rightarrow \infty} \frac{1}{T} \sum_{t} E\left[\left.\frac{\partial \omega_{t}(\theta)}{\partial \theta^{\prime}}\right|_{\theta_{0}}\right]$, and $F=\lim _{T \rightarrow \infty} \frac{1}{T} \sum_{t} E\left[\omega_{t}\left(\theta_{0}\right) \omega_{t}\left(\theta_{0}\right)^{\prime}\right]$.

Therefore, the second test can be conducted as follows [32]:

1) If the small $\sigma$ assumption is accepted, BC MLE and the robust estimator are compared. Under the assumption of homoscedsticity,

$$
\sqrt{T}\left(\hat{\lambda}_{B C}-\hat{\lambda}_{N}\right) \rightarrow N\left(0, a_{1}^{\prime} B a_{1}+d_{1}^{\prime} F d_{1}-2 a_{1}^{\prime} H d_{1}\right),
$$

where $a_{1}^{\prime}, c_{1}^{\prime}$ and $d_{1}^{\prime}$ are the first rows of $A^{-1}, C^{-1}$ and $D^{-1}$, respectively, and $H=E\left[\ell\left(\theta_{0}\right) \omega\left(\theta_{0}\right)^{\prime}\right]$. BC MLE is used if the assumption of homoscedasticity is accepted, and robust estimator otherwise.

2) If the small $\sigma$ assumption is rejected, the $N$-estimator and the robust estimator are compared. The asymptotic distribution of $\sqrt{T}\left(\hat{\lambda}_{N}-\hat{\lambda}_{R}\right)$ is given by

$$
\sqrt{T}\left(\hat{\lambda}_{N}-\hat{\lambda}_{R}\right) \rightarrow N\left(0, c_{1}{ }^{\prime} B c_{1}+d_{1}{ }^{\prime} F d_{1}-2 c_{1}{ }^{\prime} H^{*} d_{1}\right),
$$

where $H^{*}=E\left[\ell^{*}\left(\theta_{0}\right) \omega\left(\theta_{0}\right)^{\prime}\right]$. The $N$-estimator is used if the assumption of homoscedasticity is accepted, and 
the robust estimator otherwise. Unlike the previous test, estimating the variances in Equations (9) and (10) is often difficult. However, since

$$
\left\{\sqrt{V\left(\hat{\lambda}_{B C}\right)}-\sqrt{V\left(\hat{\lambda}_{R}\right)}\right\}^{2} \leq V\left(\hat{\lambda}_{B C}-\hat{\lambda}_{R}\right) \leq\left\{\sqrt{V\left(\hat{\lambda}_{B C}\right)}+\sqrt{V\left(\hat{\lambda}_{R}\right)}\right\}^{2},
$$

we can perform the second test without the rather complicated calculation of matrices.

\section{Evaluation of Educational Hospitalization LOS}

\subsection{Data}

In this section, we analyze LOS for educational hospitalization of type 2 diabetic patients. The DPC code for these patients was 100070xxxxxx0x. In the case of diabetes mellitus, two DPC codes were assigned, 100070xxxxxx0x and 100070xxxxxx1x. Periods I and II and the specific hospitalization period were defined by DPC/PDPS as 8, 16, and 29 days, respectively. Medical payments in Japan are measured by points, and hospitals receive a payment of 10 yen per point. The per diem inclusive payments were 2547 points for days 1 - 7 of hospitalization, 1855 points for days 8 - 15, and 1577 points for 16 - 29 days, independent of the purpose of hospitalization.

The Department of Health Care Economics at the Tokyo Medical and Dental University collected data from 67 hospitals. The Institutional Review Boards of the University of Tokyo (number: KE12-7) and Tokyo Medical and Dental University (number: 839) approved the use of this dataset. The sample period was July-December 2008, and the total numbers of patients for all types of diabetes and those with type 2 diabetes were 4213 (ALOS $=18.3$ days) and 3,313 (ALOS = 17.3 days). Of these, 93 patients from the former group and 4 patients from the latter were classified under 100070xxxxxx1x. Among the type 2 diabetic patients, about one-third (1101) participated in educational hospitalization. The data included patients' LOS, age, gender, principal diseases as per the International Classification of Diseases (version 10) (ICD-10) by the World Health Organization (WHO), reasons for hospitalization, presence of up to four comorbidities and complications, medical treatments, placement after hospitalization, and medical costs. Comorbidities are defined as diseases other than the principal disease at the time of hospitalization, while complications are diseases that occur during hospitalization, including those related and unrelated to the principal disease. The (DPC-based) average cost per patient for educational hospitalization was 434,719 yen and the total cost for all 4213 patients was 2,313,230,070 yen, with educational hospitalization accounting for about $20 \%$ of the total cost.

We excluded data for patients treated in clinical departments that do not specialize in the treatment of diabetes, such as pediatrics, orthopedics, psychiatrics, ophthalmology, and otolaryngology. Similarly, data for patients whose disease that caused hospitalization was not diabetes-such as those with gastric cancer, polymyalgia rheumatica, primary thrombocytopenic, myocardial infarction, chronic renal failure, and sudden deafness - were excluded. Figure 1 shows that the medical expenditures of certain patients were unreasonably high compared to their LOS. Data for such patients were deemed unreliable and excluded from the analysis. Thus, the final dataset comprised 991 patients from 28 Red Cross hospitals (i.e., H1-H28) that had at least 10 educational hospitalizations. Among these hospitals, one hospital has 100 - 200 beds, three have 300 - 400, eight have 400 - 500 beds, five have 500 - 600 beds, five others have 600 - 700 beds, three have 700 - 800 beds, two have 800 - 900 beds, and one has 1000 - 1100 beds. Since the average number of beds in a general hospital is about 120, these hospitals are considered to be rather large in scale.

Table 1 summarizes LOS across the hospitals. ALOS and standard deviation (SD) were 14.63 and 6.49 days, respectively, and the skewness and kurtosis were 1.36 and 6.52 for all 28 hospitals. ALOS for H5 was the longest (23.28 days) and that for $\mathrm{H} 12$ was the shortest (6.91 days), indicating a difference of 16.4 days and that ALOS for H5 was 3.4 times higher than that of H12. The highest and lowest SDs were 10.39 (H13) and 1.30 (H25) days, with the former's SD being 8.5 times higher than that of the latter. Therefore, this study found significantly large differences in not only ALOS but also SD.

\subsection{Results of Estimation}

The explanatory variables in this study were selected on the basis of results from previous studies [9] [17] [18] [27] [28]. The Female Dummy (0: male, 1: female) was used for gender. The numbers for male and female patients were 581 and 410, respectively. Since LOS increases with patients' age, four age dummies were used: Age 60 - 64, Age 65 - 69, Age 70 - 74, and Age 75 years and above. If the participants fell within the mentioned 


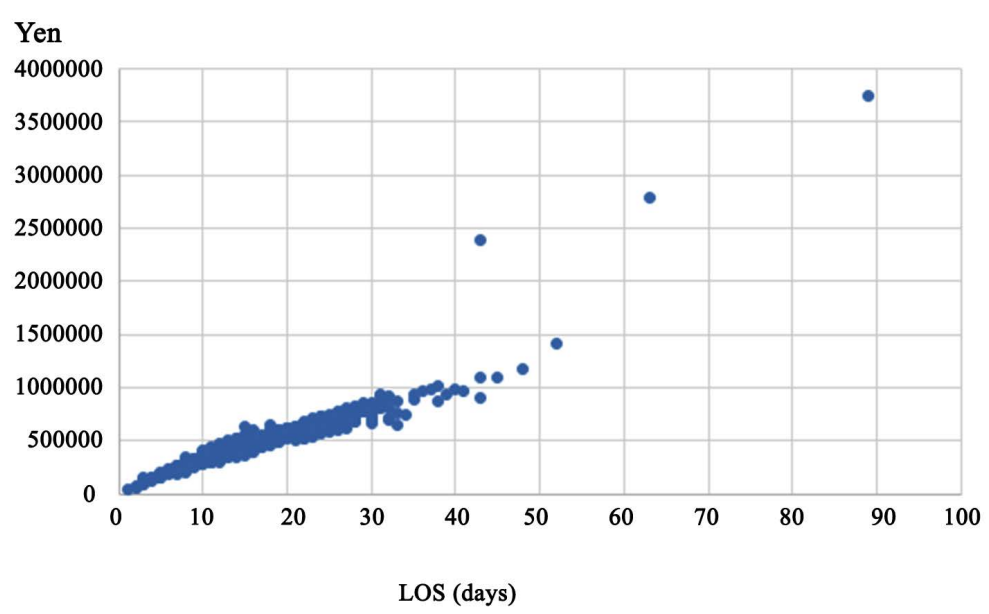

Figure 1. Medical expenditures and the LOS.

Table 1. Summary of LOS by hospital.

\begin{tabular}{|c|c|c|c|c|c|c|c|c|c|}
\hline Нp & ALOS & SD & Skewness & Kurtosis & Hр & ALOS & SD & Skeness & Kurtorsis \\
\hline $\mathrm{H} 1$ & 15.39 & 6.07 & 1.14 & 6.34 & H16 & 13.24 & 2.67 & 2.3 & 17.39 \\
\hline H2 & 20.9 & 8.87 & 0.07 & 2.22 & H17 & 15.84 & 7.01 & 0.06 & 1.96 \\
\hline H3 & 15.57 & 5.00 & 0.29 & 2.42 & H18 & 16.5 & 5.31 & 0.56 & 3 \\
\hline $\mathrm{H} 4$ & 15.82 & 5.89 & 1.21 & 3.73 & H19 & 23.16 & 6.89 & 0.25 & 3.58 \\
\hline H5 & 23.28 & 7.60 & 1.01 & 5.9 & $\mathrm{H} 20$ & 12.28 & 3.53 & -1.79 & 5.91 \\
\hline H6 & 16.38 & 3.67 & 1.63 & 5.69 & $\mathrm{H} 21$ & 15.3 & 5.97 & 2.79 & 16.09 \\
\hline $\mathrm{H} 7$ & 14.55 & 2.80 & 1.06 & 8.15 & H22 & 12.86 & 3.85 & 3.73 & 16.44 \\
\hline Н8 & 9.92 & 3.36 & -0.41 & 1.4 & $\mathrm{H} 23$ & 14.00 & 1.30 & 0.00 & 9.50 \\
\hline H9 & 16.06 & 2.68 & 0.83 & 2.7 & H24 & 13.8 & 1.42 & -0.48 & 5.18 \\
\hline H10 & 9.88 & 7.73 & 2.69 & 10.67 & H25 & 12.5 & 4.63 & 1.38 & 8.39 \\
\hline H11 & 12.37 & 3.96 & 0.52 & 2.97 & H26 & 14.6 & 6.92 & 0.69 & 2.27 \\
\hline H12 & 6.91 & 5.35 & 0.74 & 1.7 & $\mathrm{H} 27$ & 11.38 & 2.43 & 1.08 & 3.29 \\
\hline H13 & 18.07 & 10.39 & 0.75 & 2.47 & H28 & 14.71 & 5.4 & 1.46 & 4.41 \\
\hline H14 & 15.93 & 8.29 & 1.51 & 6.26 & \multirow{2}{*}{ All } & \multirow{2}{*}{14.63} & \multirow{2}{*}{6.49} & \multirow{2}{*}{1.36} & \multirow{2}{*}{6.52} \\
\hline H15 & 10.49 & 3.14 & 1.52 & 8.64 & & & & & \\
\hline
\end{tabular}

Kurtosis is the value where the normal distribution is 0 .

age groups, the value of the dummies equaled 1 , and 0 otherwise. The average age and its SD were 60.9 and 13.1 years, respectively. Comorbidities (number of comorbidities) and Complications (number of complications) were used to represent patients' conditions. Of the study's participants, 193 patients had no comorbidities and 143, 285, and 370 patients had 1, 2, and 3 comorbidities, respectively. In terms of complications, 723 had none and 116, 66, 43, and 43 had 1, 2, 3, and 4 complications, respectively. Other explanatory variables representing patients' characteristics were Acute Hospitalization, Another Hospital (i.e., introduced by another hospital), Own Outpatient, and Discharged Place (to another hospital or facility) Dummies. If the patients reported any of these characteristics, the mentioned variables were valued at 1 , and 0 otherwise. The numbers of acute hospitalizations, patients introduced by another hospital, already outpatients before hospitalization, and patients discharged to another hospital or facility were 81, 384, 933, and 189, respectively. Figure 2 shows the distribution of LOS. It shows that LOS peaked on days eight (one week after hospitalization) and 15 (two weeks after hospi- 


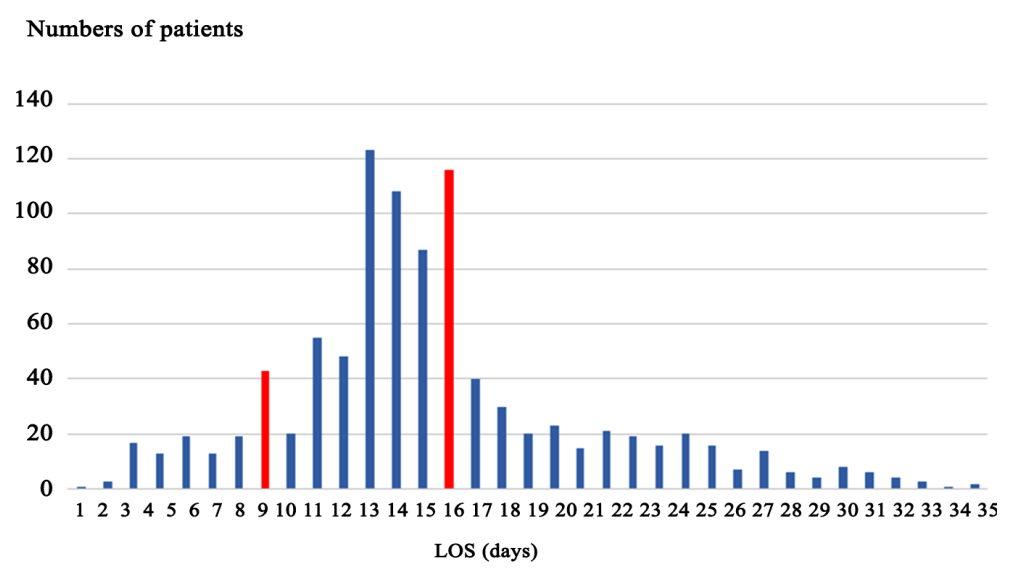

Figure 2. Numbers of patients by LOS.

talization). Therefore, Day 8 and Day 15 Dummies were added. The dummies equaled 1 if the patients LOS' was 8 or 15 days, and 0 otherwise.ICD classifications were used to represent the type of principal disease (diabetes). ICD-10 classifies diabetic patients by type of complication. The classifications include kidney complications (E11.2), ophthalmic complications (E11.3), neurological complications (E11.4), circulatory complications (E11.5), other specified complications (E11.6), multiple complications (E11.7), and without complications (E11.9). Dummy variables based on E11.9 were used to classify principal diseases. Patients 49, 36, 77, 2, 199, 296, and 332 in this study were classified under E11.2, E11.3, E11.4, E11.5, E11.6, E11.7, and E11.9, respectively. Twenty-eight hospital dummies were used to denote the influence of hospitals. These dummies were valued at 1 if hospital $i$ affected patients' LOS, and 0 otherwise. To evaluate the direct effects of hospitals, a constant term was not used.

Therefore, $x_{i j}^{\prime} \beta$ of Equation (1) can be presented as

$$
\begin{aligned}
x_{i j}^{\prime} \beta= & \beta_{1} \text { Female Dummy }+\beta_{2} \text { Age 60-64 }+\beta_{3} \text { Age } 65-69+\beta_{4} \text { Age } 70-74+\beta_{5} \text { Age } 75 \\
& +\beta_{6} \text { Comorbidities }+\beta_{7} \text { Complications }+\beta_{8} \text { Acute Hospitalization Dummy } \\
& +\beta_{9} \text { Another Hospital Dummy }+\beta_{10} \text { Own Outpatient Dummy } \\
& +\beta_{11} \text { Discharged Place Dummy }+\beta_{12} \text { Day } 8 \text { Dummy } \\
& +\beta_{13} \text { Day } 15 \text { Dummy }+\sum_{\ell} \beta_{\ell} \ell \text {-th ICD-10 Classification Dummy }+\sum_{i} \beta_{i} \text { Hospital } i \text { Dummy. }
\end{aligned}
$$

Tables 2-4 present the estimation results for BC MLE, $N$-estimator, and robust estimators, respectively. The estimates of $\lambda$ were $\hat{\lambda}_{B C}=0.3854, \hat{\lambda}_{N}=0.3901$, and $\hat{\lambda}_{R}=0.3643$. We first tested the small $\sigma$ assumption. The value of $\hat{\delta} / \sqrt{T}$ was 0.0725 , and $t=\sqrt{T}\left(\hat{\lambda}_{N}-\hat{\lambda}_{B C}\right) / \hat{\delta}=-0.0649$ was obtained from Equation (6). Therefore, the small $\sigma$ assumption was accepted at the $5 \%$ significance level. We then tested the assumption of homoscedasticity. From Equation (11), $\sqrt{V\left(\hat{\lambda}_{R}-\hat{\lambda}_{B C}\right)} \geq 0.0364$ and $t=\left|\left(\hat{\lambda}_{R}-\hat{\lambda}_{B C}\right) / \sqrt{V\left(\hat{\lambda}_{R}-\hat{\lambda}_{B C}\right)}\right| \leq 0.580$. Thus, the assumption of homoscedasticity was also accepted at the $5 \%$ significance level, indicating that BC MLE could be used in this study ${ }^{1}$. The BC MLE results were used in the remainder of this study.

The Female Dummy was not significant at the 5\% level. As for patients' age, the Age 75 Dummy was posi-

${ }^{1}$ Except Nawata's estimator [26] [28], which is adopted in this study, Powell's [44] is the only known robust estimator that is consistent under heteroscedasticity. One or more instrumental variables are needed to calculate Powell's estimator; thus, $w_{t}=\left(x_{t}{ }^{\prime} \beta\right)^{2}$ was chosen. The value of $\sum\left(\hat{x}_{t}{ }^{\prime} \beta\right)^{2} \hat{u}_{t}$ becomes zero at $\lambda=-0.01$, which means the estimate of $\lambda$ is -0.01 , where $\left\{\hat{u}_{t}\right\}$ are least squares residuals for a given value of $\lambda$. However, this is an unreasonable value, and thus, Powell's estimator is not suitable in the context of this study. 
Table 2. Results of estimation (BC MLE).

\begin{tabular}{|c|c|c|c|c|c|c|c|}
\hline Variable & Estimate & Standard Error & t-Value & Variable & Estimate & Standard Error & t-Value \\
\hline$\lambda$ & 0.3856 & 0.0185 & $20.8376^{* *}$ & \multicolumn{4}{|c|}{ Hospital Dummies } \\
\hline Female Dummy & 0.0029 & 0.0617 & 0.0464 & H6 & 4.6868 & 0.2845 & $16.4755^{* *}$ \\
\hline Age Dummies & & & & H7 & 4.0214 & 0.2425 & $16.5829^{* *}$ \\
\hline Age $60-64$ & 0.1628 & 0.1196 & 1.3612 & H8 & 3.5826 & 0.3009 & $11.9063^{* *}$ \\
\hline Age $65-69$ & 0.1328 & 0.3984 & 0.3333 & H9 & 4.3840 & 0.2513 & $17.4448^{* *}$ \\
\hline Age $70-74$ & 0.0632 & 0.1344 & 0.4702 & $\mathrm{H} 10$ & 3.3217 & 0.3087 & $10.7609^{* *}$ \\
\hline Age 75 & 0.3041 & 0.1089 & $2.7931^{* *}$ & H11 & 3.9414 & 0.2565 & $15.3650^{* *}$ \\
\hline Comorbidities & 0.1625 & 0.0493 & $3.2984^{* *}$ & H12 & 2.4138 & 0.4879 & $4.9477^{* *}$ \\
\hline Complications & 0.0689 & 0.0278 & $2.4808^{*}$ & H13 & 4.9226 & 0.5661 & $8.6950^{* *}$ \\
\hline $\begin{array}{c}\text { Acute Hospitalization } \\
\text { Dummy }\end{array}$ & 0.3954 & 0.2552 & 1.5495 & H14 & 4.2418 & 0.2935 & $14.4543^{* *}$ \\
\hline $\begin{array}{l}\text { Own Outpatient } \\
\text { Dummy }\end{array}$ & -0.1766 & 0.2629 & -0.6718 & H15 & 2.9267 & 0.3480 & $8.4104^{* *}$ \\
\hline $\begin{array}{c}\text { Another Hospital } \\
\text { Dummy }\end{array}$ & 0.1168 & 0.0858 & 1.3613 & H16 & 3.8832 & 0.2207 & $17.5920^{* *}$ \\
\hline $\begin{array}{l}\text { Discharged Place } \\
\text { Dummy }\end{array}$ & -0.1169 & 0.1021 & -1.1447 & H17 & 4.8131 & 0.3231 & $14.8962^{* *}$ \\
\hline Day 8 Dummy & -1.2820 & 0.2130 & $-6.0174^{* *}$ & H18 & 4.4489 & 0.2454 & $18.1298^{* *}$ \\
\hline Day 15 Dummy & 0.1109 & 0.0764 & 1.4525 & H19 & 5.5266 & 0.3258 & $16.9640^{* *}$ \\
\hline ICD-10 Dummies & & & & $\mathrm{H} 20$ & 3.7049 & 0.2510 & $14.7614^{* *}$ \\
\hline E11.2 & 0.1849 & 0.1382 & 1.3381 & $\mathrm{H} 21$ & 4.3259 & 0.2389 & $18.1082^{* *}$ \\
\hline E11.3 & 0.3215 & 0.2066 & 1.5561 & $\mathrm{H} 22$ & 3.9271 & 0.2437 & $16.1158^{* *}$ \\
\hline E11.4 & 0.1719 & 0.1250 & 1.3750 & $\mathrm{H} 23$ & 3.9141 & 0.2210 & $17.7122^{* *}$ \\
\hline E11.5 & 1.0280 & 0.6145 & 1.6728 & $\mathrm{H} 24$ & 4.0319 & 0.2304 & $17.4983^{* *}$ \\
\hline E11.6 & 0.1227 & 0.1306 & 0.9395 & $\mathrm{H} 25$ & 3.6641 & 0.2104 & $17.4185^{* *}$ \\
\hline E11.7 & 0.2678 & 0.1024 & $2.614^{* *}$ & $\mathrm{H} 26$ & 4.1450 & 0.5306 & $7.8127^{* *}$ \\
\hline Hospital Dummies & & & & $\mathrm{H} 27$ & 3.4998 & 0.2254 & $15.5239^{* *}$ \\
\hline H1 & 4.360945 & 0.2477 & $17.6053^{* *}$ & h28 & 4.3567 & 0.3484 & $12.5045^{* *}$ \\
\hline $\mathrm{H} 2$ & 5.055961 & 0.5439 & $9.2966^{* *}$ & & & & \\
\hline Н3 & 4.315891 & 0.3221 & $13.3981^{* *}$ & $\sigma^{2}$ & 0.9407 & 0.0078 & 121.1243 \\
\hline $\mathrm{H} 4$ & 4.108629 & 0.4444 & $9.2456^{* *}$ & $\mathrm{R} 2$ & & 0.3952 & \\
\hline $\mathrm{H} 5$ & 5.47201 & 0.3583 & $15.2728^{* * *}$ & LogL & & -2929.46 & \\
\hline
\end{tabular}

*Significant at the $5 \%$ level, **Significant at the $1 \%$ level.

tive and significant at the $1 \%$ level, and the LOS became longer for a patient aged 75 or over. Comorbidities and Complications were positive and significant at the $1 \%$ and $5 \%$ levels, respectively, indicating that comorbidities and complications prolonged LOS, as expected. Acute Hospitalization, Another Hospital, Own Outpatient, and Discharged Place Dummies were not significant at the $5 \%$ level, and the influences of these variables were not admitted. The Day 8 Dummy was negative and significant the 1\% level, but the Day 15 Dummy was not significant at the $5 \%$ level. This indicates that one-week hospitalization, and not two-week hospitalization, affected 
Table 3. Results of estimation (N-estimator).

\begin{tabular}{|c|c|c|c|c|c|c|c|}
\hline Variable & Estimate & Standard Error & t-Value & Variable & Estimate & Standard Error & t-Value \\
\hline$\lambda$ & 0.3901 & 0.0012 & 323.1980 & \multicolumn{4}{|c|}{ Hospital Dummies } \\
\hline Female Dummy & 0.0028 & 0.0624 & 0.0450 & H5 & 5.5193 & 0.2383 & 23.1644 \\
\hline Age Dummies & & & & H6 & 4.7223 & 0.2566 & 18.4008 \\
\hline Age 60 - 64 & 0.1652 & 0.0989 & 1.6704 & H7 & 4.0496 & 0.2373 & 17.0630 \\
\hline Age 65 - 69 & 0.1348 & 0.0927 & 1.4535 & H8 & 3.6048 & 0.3013 & 11.9648 \\
\hline Age $70-74$ & 0.0646 & 0.1127 & 0.5727 & H9 & 4.4158 & 0.2280 & 19.3676 \\
\hline Age 75 & 0.3083 & 0.0916 & 3.3641 & $\mathrm{H} 10$ & 3.3432 & 0.3136 & 10.6603 \\
\hline Comorbidities & 0.1643 & 0.0341 & 4.8244 & H11 & 3.9676 & 0.2432 & 16.3123 \\
\hline Complications & 0.0697 & 0.0280 & 2.4929 & H12 & 2.4268 & 0.4865 & 4.9880 \\
\hline $\begin{array}{c}\text { Acute } \\
\text { Hospitalization Dummy }\end{array}$ & 0.4010 & 0.2288 & 1.7523 & H13 & 4.9633 & 0.3825 & 12.9763 \\
\hline $\begin{array}{l}\text { Own Outpatient } \\
\text { Dummy }\end{array}$ & -0.1785 & 0.1782 & -1.0022 & H14 & 4.2729 & 0.2698 & 15.8353 \\
\hline $\begin{array}{l}\text { Another Hospital } \\
\text { Dummy }\end{array}$ & 0.1184 & 0.0790 & 1.4990 & H15 & 2.9403 & 0.3257 & 9.0271 \\
\hline $\begin{array}{l}\text { Discharged Place } \\
\text { Dummy }\end{array}$ & -0.1183 & 0.0965 & -1.2260 & H16 & 3.9085 & 0.2235 & 17.4897 \\
\hline Day 8 Dummy & -1.2986 & 0.1373 & -9.4574 & H17 & 4.8511 & 0.2344 & 20.6930 \\
\hline Day 15 Dummy & 0.1110 & 0.0799 & 1.3897 & H18 & 4.4818 & 0.2196 & 20.4053 \\
\hline ICD-10 Dummies & & & & H19 & 5.5749 & 0.2576 & 21.6441 \\
\hline E11.2 & 0.1866 & 0.1373 & 1.3587 & $\mathrm{H} 20$ & 3.7290 & 0.2499 & 14.9215 \\
\hline E11.3 & 0.3254 & 0.2048 & 1.5888 & H21 & 4.3578 & 0.2299 & 18.9580 \\
\hline E11.4 & 0.1738 & 0.1217 & 1.4287 & $\mathrm{H} 22$ & 3.9527 & 0.2216 & 17.8369 \\
\hline E11.5 & 1.0407 & 0.5884 & 1.7687 & $\mathrm{H} 23$ & 3.9396 & 0.2238 & 17.6047 \\
\hline E11.6 & 0.1236 & 0.1133 & 1.0905 & $\mathrm{H} 24$ & 4.0589 & 0.2333 & 17.4004 \\
\hline E11.7 & 0.2710 & 0.0941 & 2.8789 & H25 & 3.6872 & 0.2104 & 17.5286 \\
\hline Hospital Dummies & & & & $\mathrm{H} 26$ & 4.1745 & 0.5209 & 8.0145 \\
\hline H1 & 4.3932 & 0.2448 & 17.9485 & $\mathrm{H} 27$ & 3.5204 & 0.2253 & 15.6261 \\
\hline $\mathrm{H} 2$ & 5.0982 & 0.4526 & 11.2647 & h28 & 4.3881 & 0.3289 & 13.3436 \\
\hline H3 & 4.3467 & 0.3134 & 13.8680 & $\sigma^{2}$ & 0.9638 & 0.0063 & 154.0597 \\
\hline $\mathrm{H} 4$ & 4.1374 & 0.4173 & 9.9147 & R2 & & 0.3953 & \\
\hline
\end{tabular}

discharge decisions in hospitals. As for ICD-10 classifications, E11.7 was significant at the $1 \%$ level, while the other estimates were not significant at the 5\% level. Patients classified under E11.7 had multiple complications. Although classification problems may exist ${ }^{2}$, they are consistent with the results for comorbidities and complications. In other words, higher comorbidities and complications worsen a patient's condition and prolong LOS. For the hospital dummies, the maximum and minimum estimates were 5.527 for H19 and 2.414 for H12,

${ }^{2}$ Classification problems may exist among DPC codes, comorbidities, complications, and IDC-10 classifications. Since DPC codes are determined by the principal disease - for which most medical resources were used during hospitalization-and not the disease that causes hospitalization, some ambiguity may exist in their classifications among hospitals. For example, neither comorbidities nor complications were reported for 7, 6, 6, 8, 17, and 34 patients classified under E11.2, E11.3, E11.4, E11.6, and E11.7, respectively. These patients should have been classified under E11.9. On the other hand, among the 324 patients classified under E11.9, 224 had comorbidities, 58 had complications and only 93 were free from comorbidities and complications. Diabetic patients with the DPC code 100070xxxxxx0x had similar medical payments, independent of the IDC-10 classifications. Although the findings of the analysis-comorbidities and complications prolonged LOS - were not affected by these problems, establishing a standard classification method across hospitals seems crucial to improve the quality of data in the future. 
Table 4. Results of estimation (Robust-estimator).

\begin{tabular}{|c|c|c|c|c|c|c|c|}
\hline Variable & Estimate & Standard Error & t-Value & Variable & Estimate & Standard Error & $\mathrm{t}$-Value \\
\hline$\lambda$ & 0.3643 & 0.0079 & 45.9743 & \multicolumn{4}{|c|}{ Hospital Dummies } \\
\hline Female Dummy & 0.0031 & 0.0582 & 0.0533 & H5 & 5.2658 & 0.2208 & 23.8531 \\
\hline Age Dummies & & & & H6 & 4.5313 & 0.2387 & 18.9797 \\
\hline Age 60 - 64 & 0.1528 & 0.0914 & 1.6720 & H7 & 3.8976 & 0.2226 & 17.5126 \\
\hline Age 65 - 69 & 0.1241 & 0.0860 & 1.4428 & H8 & 3.4850 & 0.2833 & 12.3030 \\
\hline Age $70-74$ & 0.0574 & 0.1042 & 0.5513 & H9 & 4.2448 & 0.2125 & 19.9787 \\
\hline Age 75 & 0.2861 & 0.0850 & 3.3657 & H10 & 3.2275 & 0.2977 & 10.8399 \\
\hline Comorbidities & 0.1549 & 0.0324 & 4.7860 & H11 & 3.8266 & 0.2271 & 16.8530 \\
\hline Complications & 0.0654 & 0.0263 & 2.4822 & H12 & 2.3565 & 0.4634 & 5.0852 \\
\hline $\begin{array}{c}\text { Acute Hospitalization } \\
\text { Dummy }\end{array}$ & 0.3710 & 0.2052 & 1.8085 & $\mathrm{H} 13$ & 4.7454 & 0.3424 & 13.8579 \\
\hline $\begin{array}{l}\text { Own Outpatient } \\
\text { Dummy }\end{array}$ & -0.1683 & 0.1698 & -0.9910 & H14 & 4.1054 & 0.2505 & 16.3906 \\
\hline $\begin{array}{l}\text { Another Hospital } \\
\text { Dummy }\end{array}$ & 0.1100 & 0.0737 & 1.4927 & H15 & 2.8662 & 0.2965 & 9.6657 \\
\hline $\begin{array}{l}\text { Discharged Place } \\
\text { Dummy }\end{array}$ & -0.1110 & 0.0906 & -1.2251 & H16 & 3.7722 & 0.2082 & 18.1186 \\
\hline Day 8 Dummy & -1.2099 & 0.1219 & -9.9285 & H17 & 4.6471 & 0.2188 & 21.2380 \\
\hline Day 15 Dummy & 0.1105 & 0.0757 & 1.4593 & H18 & 4.3046 & 0.2045 & 21.0470 \\
\hline ICD-10 Dummies & & & & H19 & 5.3163 & 0.2385 & 22.2923 \\
\hline E11.2 & 0.1777 & 0.1297 & 1.3702 & $\mathrm{H} 20$ & 3.5992 & 0.2348 & 15.3262 \\
\hline E11.3 & 0.3046 & 0.1890 & 1.6114 & $\mathrm{H} 21$ & 4.1861 & 0.2140 & 19.5622 \\
\hline E11.4 & 0.1637 & 0.1138 & 1.4378 & H22 & 3.8149 & 0.2062 & 18.5046 \\
\hline E11.5 & 0.9731 & 0.5470 & 1.7790 & $\mathrm{H} 23$ & 3.8021 & 0.2086 & 18.2271 \\
\hline E11.6 & 0.1188 & 0.1086 & 1.0943 & H24 & 3.9132 & 0.2177 & 17.9774 \\
\hline E11.7 & 0.2542 & 0.0880 & 2.8886 & $\mathrm{H} 25$ & 3.5624 & 0.1961 & 18.1664 \\
\hline Hospital Dummies & & & & $\mathrm{H} 26$ & 4.0158 & 0.4860 & 8.2630 \\
\hline H1 & 4.2198 & 0.2304 & 18.3183 & $\mathrm{H} 27$ & 3.4093 & 0.2097 & 16.2610 \\
\hline $\mathrm{H} 2$ & 4.8717 & 0.4191 & 11.6243 & h28 & 4.2193 & 0.3061 & 13.7829 \\
\hline H3 & 4.1810 & 0.2925 & 14.2940 & $\sigma^{2}$ & & 0.8437 & \\
\hline
\end{tabular}

indicating a difference of 3.113-this figure is much higher than the effects of the other variables. Figure 3 illustrates the relationship between ALOS and the estimates of the hospital dummies. The correlation coefficient was 0.947 , and there was an almost linear relationship between the two variables. Surprisingly, despite controlling for patient characteristics, significant differences remain across hospitals.

\section{Discussion}

The estimates of the dummy variables demonstrate the net effects of hospitals on ALOS, thus eliminating the effects of patient characteristics. In other words, LOS for education hospitalization is largely determined by hospitals, and patient characteristics have only a minor influence. As shown in the previous section, significant differences were found across hospitals. Therefore, I examined hospital and regional factors affecting ALOS using the following regression model:

$\beta_{i}=\gamma_{1}+\gamma_{2} \log ($ Beds $)+\gamma_{3}$ Bed Density $+\gamma_{4} \log ($ Population Density $)+\gamma_{5}$ Average Stay $+\gamma_{6}$ Temperature 


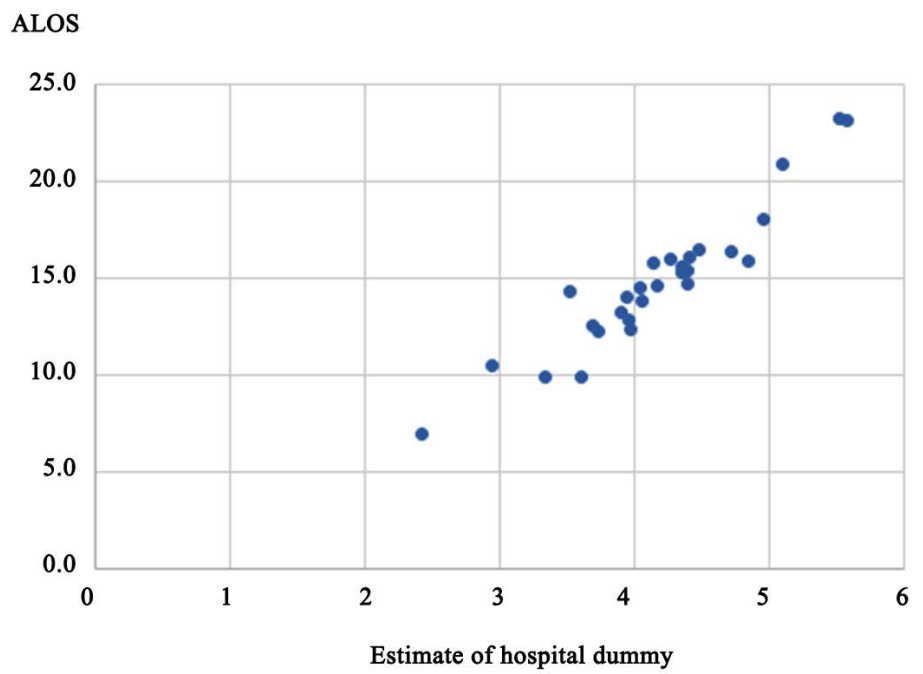

Figure 3. ALOSs and estimates of hospital dummies.

where $\beta_{i}$ is the estimate of Hospital $i$ Dummy,Beds denotes the number of beds and the size of the hospital, Bed Density is the number of beds per 100 thousand people, Population Density is population density per $\mathrm{km}^{2}$, and Average Stay is the ALOS of all patients for general hospitals in the prefecture where the hospital is located. These data were obtained by the hospital survey [33] and the 2010 National Census data [34]. Bed Density and Population Density are represented competition among hospitals and ease of access to hospitals in the region. Average Stay denotes a rough standard of ALOS in the region. Weather may also be a factor hindering the commute to hospitals, especially in cold regions. Temperature is the average annual temperature between 1981 and 2010, recorded at the closest observation point from the hospital [35]. Since all 28 hospitals were Red Cross hospitals, the effect of management was not considered.

The estimation results are provided in Table 5. The standard errors are calculated using the robust estimation method [36]. The estimate of Average Stay was positive and significant at the 5\% level. In other words, regional hospitalizations with prolonged ALOS indicated that the hospitals tended to keep their patients for longer terms. Thus, the regional standard of ALOS affected hospitals' behavior.

According to a hospital survey conducted by the Osaka Prefectural Government [37], 115 hospitals had educational programs and ALOS varied from a few days to few weeks across the hospitals. The survey also pointed out the poor quality of educational programs; for example, only few hospitals had patient associations that encouraged patients to help each other and exchange correct information about diabetes before and after hospitalization. In fact, some hospitals did not have clinical paths for educational programs. The report also emphasized the importance of regional corporations among hospitals. Reducing ALOS for educational hospitalization by half the time (e.g., from 14 to 7 days) can save as much as 100 billion yen in medical expenses. However, DPC hospitals are required to satisfy certain criteria $^{3}$, as a result of which their costs are considerably higher than those of small-scale hospitals and clinics. Thus, substantial investments in medical resources for educational hospitalization are a viable option for such hospitals. In other words, future medical policies to control medical costs in Japan must also consider the productivity of hospitals [38]. Evidently, some hospitals must also improve their educational hospitalizations_-for example, by ensuring better management of hospitalization schedules [39] —and modify their programs [40] [41] to reduce ALOS. Regional corporations, hospital networks, clinics, and local administrations such as prefectural governments and public healthcare centers could help realize such improvements. In addition, local corporations and networks can care for diabetic patients before and after hospitalization. This way, patients can join relevant associations, obtain accurate information about diabetes at public

\footnotetext{
${ }^{3}$ The basic criteria to qualify as a DPC hospital are as follows [45]: 1) A hospital must provide acute medical care, and the patient-nurse ratio must be 7:1 or 10:1. (In Japan, hospitals are classified into four categories on the basis of patient-nurse ratios. They are 7:1, 10:1, 13:1, and 15:1. The medical payments to hospitals are determined by these categories.) 2) A hospital must participate in DPC surveys and provide proper data to those conducting the surveys. 3) A hospital must set up a coding committee for accurate DPC coding. The committee members must comprise a person in charge of coding, a medical doctor, a pharmacist, and an individual from a division that records medical information or handles medical payments. A committee meeting must be held at least twice a year.
} 
Table 5. Hospital and regional factors which might affect the LOS.

\begin{tabular}{cccc}
\hline Variable & Estimate & Standard Error & t-Value \\
\hline Constant & -1.8923 & 3.1655 & -0.5978 \\
Log (Beds) & 0.2824 & 0.2652 & 1.0648 \\
Bed Density & -0.0012 & 0.0006 & -2.0401 \\
Log (Population Density) & 0.1404 & 0.1588 & 0.8839 \\
Average Stay & 0.3002 & 0.1411 & $2.128^{*}$ \\
Temperature & -0.0528 & 0.046 & -1.1476 \\
R2 & & 0.2456 & \\
\hline
\end{tabular}

*Significant at the $5 \%$ level.

healthcare centers, and receive periodic medical checks at clinics in their residential areas rather than regularly visiting a hospital

Cavan et al. [42] associated the introduction of ward-based nurse advisors for diabetes patients in January 1998 with significant reductions in LOS for inpatients with diabetes in the United Kingdom. Puig et al. [43] evaluated the impact of consultation by an endocrinology team on the LOS of diabetic patients in a Spanish hospital's short-stay unit and reported that consultation reduced patients' LOS. Such approaches can be adopted in Japan to improve regional corporations' educational programs for diabetic patients.

\section{Conclusions}

This study analyzed LOS of educational hospitalizations for 991 type 2 diabetic patients in 28 Red Cross hospitals using the BC model. The results of the Hausman test indicated that BC MLE could be used for the purpose of this analysis. The variables found to affect LOS were patients' age (75 and above), numbers of comorbidities and complications, the day 8 dummy, and the principal disease classification E11.7. The analysis also found significant differences in the LOS across hospitals, even after controlling for patient characteristics. This proves that LOS is primarily affected by hospitals, while patient characteristics have only marginal effects. In addition, it was found that ALOS for all patients in general hospitals in a given prefecture affected LOS. Thus, it may be necessary for some hospitals to revise their current educational programs by improving their management of hospitalization schedules and adopting appropriate educational programs for the effective use of medical resources. This can be easily facilitated by regional corporations, hospital networks, clinics, and administrations, such as prefectural governments and public healthcare centers. Regional corporations and networks can also facilitate caring for patients before as well as after hospitalization.

With the introduction of DPC/PDPS, an enormous amount of medical information has been computerized. Future research can access this information to evaluate other important diseases to facilitate the effective use of medical resources.

\section{Acknowledgements}

This study was supported by a Grant-in-Aid for Scientific Research, "Analyses of Large Scale Medical Survey Data and the Policy Evaluations in Japan (Grant Number: 24330067)," from the Japan Society of Science. We would like to thank two anonymous referees and Prof. Yoshiyuki Takeuchi of Osaka University for their helpful comments and suggestions.

\section{References}

[1] Ministry of Health, Labour and Welfare (2013) Hesiei 23 nendo kokumin iryouhi (National Medical Expenditures, Fiscal Year 2011, in Japanese).

[2] American Diabetes Association (2013) Economic costs of diabetes in the US in 2012. Diabetes Care, 36, $1033-1046$. http://dx.doi.org/10.2337/dc12-2625

[3] Danaei, G., Finucane, M.M., Lu, Y., et al. (2011) National, Regional and Global Trends in Fasting Plasma Glucose and 
Diabetes Prevalence since 1980: Systematic Analysis of Health Examination Surveys and Epidemiological Studies with 370 Country-Years and 2.7 Million Participants. Lancet, 378, 31-40. http://dx.doi.org/10.1016/S0140-6736(11)60679-X

[4] Cromarty, J., Parikh, S., Lim, W.K., et al. (2014) Effects of Hospital-Acquired Conditions on Length of Stay for Patients with Diabetes. Internal Medicine Journal, 44, 1109-1116. http://dx.doi.org/10.1016/S0140-6736(11)60679-X

[5] Kuroe, A., Fukushima, M. and Kiyose, H. (2007) 2 gata tounyoubyou no seiin to byoutai (Causes and Conditions of the Type 2 Diabetes Mellitus). In: Kadikawa, T., et al., Eds., Tounyoubyou-gaku—Kiso to rinnshou (Diabetology—Basics and Clinical Practices). Mishimura-Shoten, Tokyo, 294-305. (In Japanese)

[6] Healy, S.J, Black, D., Harris, C., et al. (2013) Inpatient Diabetes Education Is Associated with Less Frequent Hospital Readmission among Patients with Poor Glycemic Control. Diabetes Care, 36, 2960-2967. http://dx.doi.org/10.2337/dc13-0108

[7] Centers for Disease and Prevention (2014) Average Length of Stay (LOS, in Days) of Hospital Discharges with Diabetes as First-Listed Diagnosis, United States 1988-2009. http://www.cdc.gov/diabetes/statistics/dmfirst/fig2.htm

[8] Ncube-Zulu, T. and Danckwerts, M. (2014) Comparative Hospitalization Cost and Length of Stay between Patients with and without Diabetes in a Large Tertiary Hospital in Johannesburg, South Africa. International Journal of Dabetes in Developing Countries, 34, 156-162. http://dx.doi.org/10.1007/s13410-013-0173-8

[9] Kudo, T, Fujino, Y., Matsuura, A., et al. (2011) Prevalence of Type 2 Diabetes among Acute Inpatients and Its Impact on Length of Hospital Stay in Japan Diabetes Mellitus and the Risk of Cancer: Results from a large-Scale Population-Based Cohort Study in Japan. Internal Medicine, 50, 405-411. http://dx.doi.org/10.1007/s13410-013-0173-8

[10] Inoue M., M. Iwasak, T. Otani et al. (2006) Diabetes Mellitus and the Risk of Cancer. Archives of International Medicine, 166, 1871-1877. http://dx.doi.org/10.1001/archinte.166.17.1871

[11] Nirantharakumar, K., Marshall, T., Kennedy, A., Narendran, P., Hemming, K. and Coleman, J.J. (2012) Hypoglycaemia Is Associated with Increased Length of Stay and Mortality in People with Diabetes Who Are Hospitalized. Diabetic Medicine, 29, e445-e448. http://dx.doi.org/10.1111/dme.12002

[12] Parappil, A., Depczynski, B., Collett, P. and Marks, G.B. (2010) Effect of Comorbid Diabetes on Length of Stay and Risk of Death in Patients Admitted with Acute Exacerbations of COPD. Respirology, 15, 918-922. http://dx.doi.org/10.1111/j.1440-1843.2010.01781.x

[13] Nirantharakumar, K., Saeed, M., Wilson, I., Marshall, T. and Coleman, J.J. (2013) In-Hospital Mortality and Length of Stay in Patients with Diabetes Having Foot Disease. Journal of Diabetes and Its Complications, 27, 454-458. http://dx.doi.org/10.1016/j.jdiacomp.2013.05.003

[14] Nirantharakumar, K., Toulis, K.A., Wijesinghe, H., Mastana, M.S., Srikantharajaha, M., Bhatta, S., et al. (2013) Impact of Diabetes on Inpatient Mortality and Length of Stay for Elderly Patients Presenting with Fracture of the Proximal Femur. Journal of Diabetes and Its Complications, 27, 208-210. http://dx.doi.org/10.1016/j.jdiacomp.2012.11.010

[15] Sharma, A., Muir, R., Johnston, R., Carter, E., Bowden, G. and Wilson-MacDonald, J. (2013) Diabetes Is Predictive of Longer Hospital Stay and Increased Rate of Complications in Spinal Surgery in the UK. Annals of the Royal College of Surgeons of England, 95, 275-279. http://dx.doi.org/10.1308/003588413X13511609958299

[16] Cook, C.B., Hentz, J.G., Miller, W.J., Tsui, C., Naylor, D.B., Ziemer, D.C. and Waller, L.A. (2007) Relationship of Diabetes with Cardiovascular Disease-Related Hospitalization Rates, Length of Stay, and Charges: Analysis by Race/Ethnicity, Age, and Sex. Ethnicity \& Disease, 17, 714-720.

[17] Mutou, K., Uchigata, Y. and Yamada, H. (1999) 18 sai miman hasshou IDDM kanja nonyuuin nissu ni kansuru chousa (Investigation on Ospitalization Days in Crisis of IDDM Child Patients under 18 Years Old). Purakutisu (Journal of Practical Diabetes), 16, 302-306. (In Japanese)

[18] Sohmiya, M., Yonehara, S., Sumikawa, M., et al. (2004) Tounyoubyou no nyuuin nissuu ni eikyou wo oyobosu youin ni kansuru kentou (Review of the Factors Influencing the Diabetic Patients' LOS in the Hospital). Rinsyou to Kenkyuu (The Japanese Journal of Clinical and Experimental Medicine), 81, 1031-1033. (in Japanese)

[19] DPC Evaluation Division, Central Social Insurance Medical Council (2010) Heisei 24 nendo kaite ni muketa DPC seido (DPC/PDPS) no taiou nit suite (Concerning the Steps for the 2012 Revision of the DPC System DPC/PDPS). Tokyo. (In Japanese)

[20] Central Social Insurance Medical Council (2014) DPC taishou hyouin Junbi hyouin no kibo (heisei 26 nen 4 gatsu 1 nichi) mikomi (Estimated Sizes of DPC Hospitals and Preparing Hospitals as of April 1st, 2014, in Japanese). Tokyo.

[21] Ministry of Health, Labour and Welfare (2014) Heisei 25 nenndo byoin houkoku (Hospital Survey, Fiscal Year 2013, in Japanese). Tokyo.

[22] Nawata, K., Ii, M., Toyama, H. and Takahashi, T. (2009) Evaluation of the Inclusive Payment System Based on the Diagnosis Procedure Combination with Respect to Cataract Operations in Japan. Health, 1, 93-103. http://dx.doi.org/10.4236/health.2009.12016 
[23] Shimizu, Takahashi, K., Tanaka, M., et al. (2007) DPC dounyu ni tomonau shinryoujouhou deta no katsuyou houhou (Utilization of Clinical Data Increase in Medical Care Quality and Income Following the Introduction of DPC). Aijinkai igaku kenkyushi (Aijinkai Medical Research Journal), 39, 50-52. (In Japanese)

[24] Box, G.E.P. and Cox, D.R. (1964) An Analysis of Transformation. Journal of the Royal Statistical Society B, 26, 211252.

[25] Nawata, K. (2013) A New Estimator of the Box-Cox Transformation Model Using Moment Conditions. Economics Bulletin, 33, 2287-2297.

[26] Nawata, K. (2013) Robust Estimation Based on the First- and Third-Moment Restrictions of the Power Transformation Model. Proceedings, International Congress on Modelling and Simulation (MODSIM 2013), 1284-1290. http://www.mssanz.org.au/modsim2013/F4/nawata2.pdf

[27] Nawata, K. (2014) A New Test for the Box-Cox Transformation Model. Economics Bulletin, 34, 324-332.

[28] Nawata, K. (2014) A Semiparametric Estimator that Requires neither Specific Distributions nor an i.i.d Condition of the Error Terms and Tests for the Box-Cox Transformation. IPRC Working Paper No. 13, University of Tokyo. http://ipr-ctr.t.u-tokyo.ac.jp/jp/libraries/dp/DP13.pdf

[29] Bickel, P.J. and Doksum, K.A. (1981) An Analysis of Transformations Revisited. Journal of the American Statistical Association, 76, 296-311. http://dx.doi.org/10.1080/01621459.1981.10477649

[30] Hausman, J. (1978) Specification Tests in Econometrics. Econometrica, 46, 1251-1271. http://dx.doi.org/10.2307/1913827

[31] Nawata, K. and McAleer, M. (2014) The Maximum Number of Parameters for the Hausman Test When the Estimators Are from Different Sets of Equations. Economics Letters, 123, 291-294. http://dx.doi.org/10.1016/j.econlet.2014.03.005

[32] Nawata, K. and Kawabuchi, K. (2014) Evaluation of the 2006 Revision of the Medical Payment System in Japan by the Box-Cox Transformation Model and the Hausman Test. IPRC Working Paper No. 15, University of Tokyo. http://ipr-ctr.t.u-tokyo.ac.jp/jp/libraries/dp/DP15.pdf

[33] Ministry of Health, Labour and Welfare (2009) Heisei 21 nenndo byoin houkoku (Hospital Survey, Fiscal Year 2009, in Japanese). Tokyo.

[34] Statistics Bureau, Ministry of Internal Affairs and Communications (2011) Heisei 22 nenndo kokusei chosa (National Census of 2010, in Japanese). Tokyo.

[35] National Astronomical Observatory of Japan, Ed. (2014) Rika nenpyo heisei 27 nen (Chronological Science Tables 2014). Maruzen shuppan, Tokyo. (In Japanese)

[36] White, H. (1980) A Heteroskedasticity-Consistent Covariance Matrix Estimator and a Direct Test for Heteroskedasticity. Econometrica, 48, 817-838. http://dx.doi.org/10.2307/1912934

[37] Osaka Prefecture Government (2008) Osaka-fu hoken keikaku (Health Planning in Osaka Prefecture, in Japanese). Osaka.

[38] Mokikawa, M. (2010) Biyouin no seisansei (Productivities of Hospitals). RIETI Discussion Paper Series10-J-041, Tokyo. (In Japanese)

[39] Vissers, J.M.H., Van Der Bij, J.D. and Kusters, R.J. (2001) Towards Decision Support for the Waiting Lists: An Operations Management View. Health Care Management Science, 4, 133-142. http://dx.doi.org/10.1023/A:1011409711828

[40] Ghodeswar, B.M. and Vaidyanathan, J. (2006) Adoption of Medical Technology by Hospitals: A Review of Innovation Attributes and a Conceptual Model of the Resulting Service. World Review of Science, Technology and Sustainable Development, 3, 362-380. http://dx.doi.org/10.1504/WRSTSD.2006.011114

[41] Cogen, F.R., Johnson, P.A., Pastor, W. and Kaplowitz, P.B. (2008) Length of Stay Safely Reduced with a Diabetes Clinical Pathway in an Urban Children's Hospital. Journal of Clinical Outcomes Management, 15, 384-392.

[42] Cavan, D.A., Hamilton, P., Everett, J. and Kerr, D. (2001) Reducing Hospital Inpatient Length of Stay for Patients with Diabetes. Diabetic Medicine, 18, 162-164. http://dx.doi.org/10.1046/j.1464-5491.2001.00420.x

[43] Puig, J., Supervia, A., Marquez, M.A., Flores, J., Cano, J.F. and Gutiérrez, J. (2007) Diabetes Team Consultation: Impact on Length of Stay of Diabetic Patients Admitted to a Short-Stay Unit. Diabetes Research and Clinical Practice, 78, 211-216. http://dx.doi.org/10.1016/j.diabres.2007.03.010

[44] Powell, J.L. (1996) Rescaled Method-of-Moments Estimation for the Box-Cox Regression Model. Economics Letters, 51, 259-265. http://dx.doi.org/10.1016/0165-1765(96)00811-7

[45] Ministry of Health, Labour and Welfare (2014) DPC seido heno sannkatou no tetsuduki nit suite (Concerning Procedures to Join the DPC System and Related Matters, in Japanese). Tokyo. 
Scientific Research Publishing (SCIRP) is one of the largest Open Access journal publishers. It is currently publishing more than 200 open access, online, peer-reviewed journals covering a wide range of academic disciplines. SCIRP serves the worldwide academic communities and contributes to the progress and application of science with its publication.

Other selected journals from SCIRP are listed as below. Submit your manuscript to us via either submit@scirp.org or Online Submission Portal.
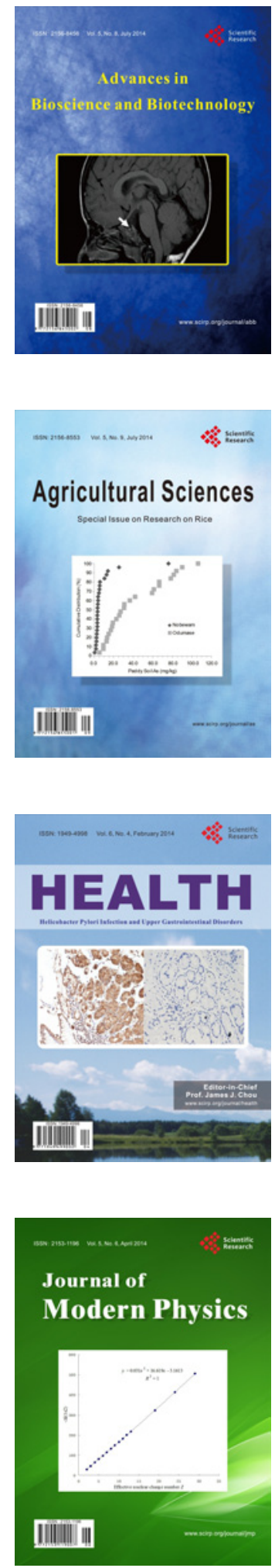
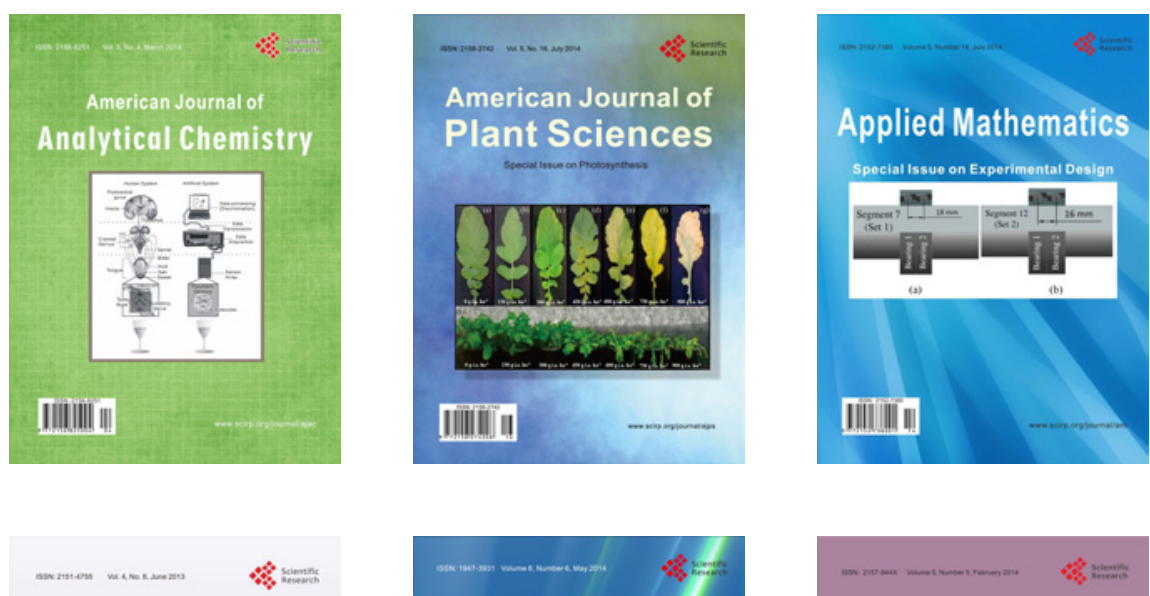

Creative Education
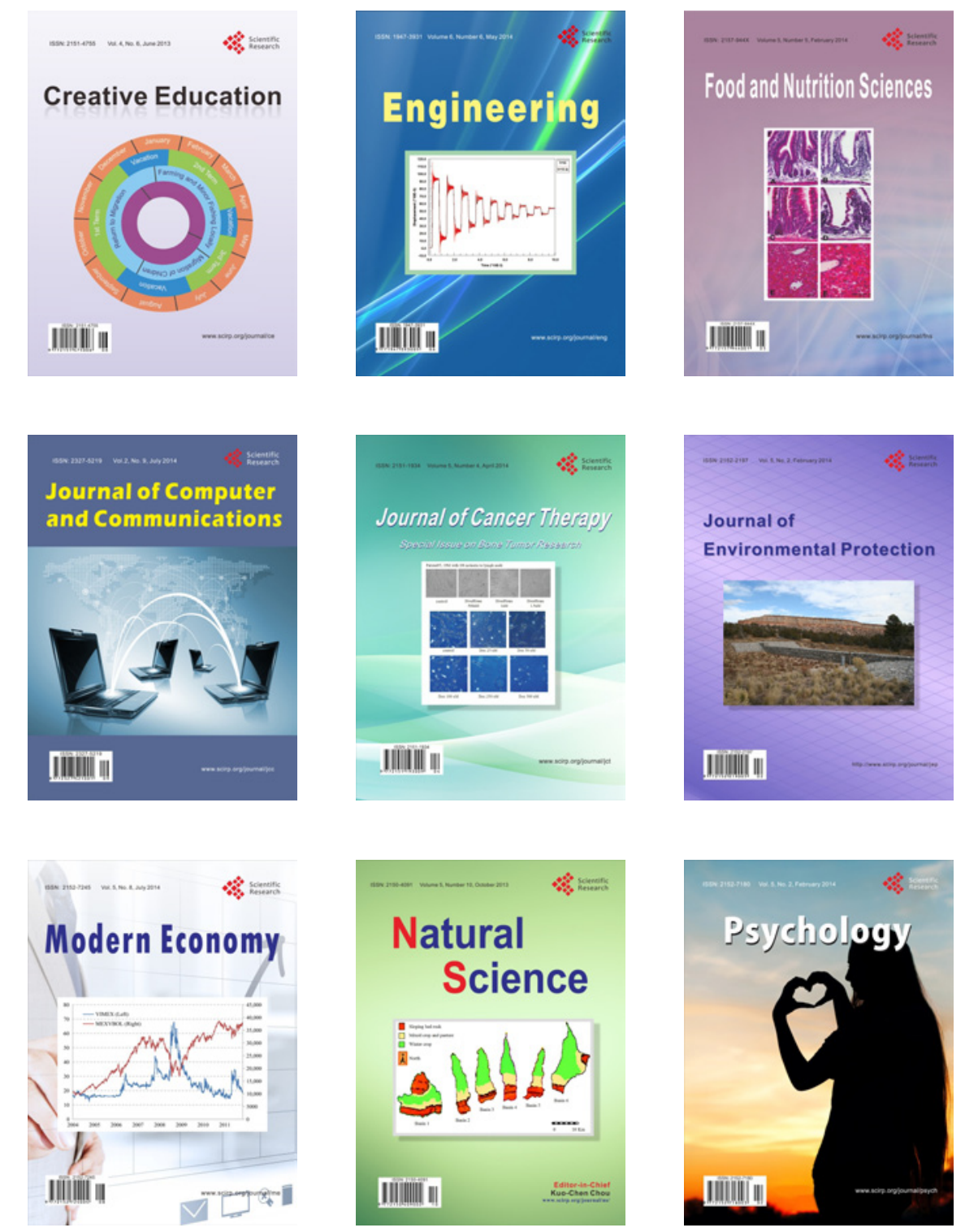